\title{
Alterations in angina threshold with nifedipine during pacing induced angina
}

\author{
PAUL H KRAMER, KANU CHATTERJEE, ALAN SCHWARTZ, KARL SWEDBERG, * \\ JEAN-LUCIEN ROULEAU, $†$ DEIRDRE CURRAN, LETHA BLEVINS, \\ WILLIAM W PARMLEY \\ From the Cardiovascular Division, Department of Medicine, and the Cardiovascular Research Institute, University of \\ California, San Francisco, USA
}

SUMMARY Changes in coronary haemodynamics and angina threshold were determined during atrial pacing in 11 patients with fixed obstructive coronary artery disease with effort angina before and after the administration of $20 \mathrm{mg}$ of oral nifedipine. Coronary vascular resistance decreased at resting and at "subangina" heart rates but not at "angina" rates. Primary coronary vasodilatation with nifedipine was also suggested by higher coronary sinus oxygen content whether at rest or at subangina or angina heart rates. After nifedipine angina occurred at a lower double product and lower myocardial oxygen consumption.

These findings suggest that nifedipine is a coronary vasodilator, but angina can occur at a lower angina threshold in some patients with obstructive coronary artery disease.

The imbalance between myocardial oxygen supply and demand is the principal mechanism of anginathe clinical manifestation of myocardial ischaemia. Primary decrease in coronary blood flow (oxygen supply), due to increased vasomotor tone or frank spasm of the epicardial conduit coronary arteries, appears to be the cause of myocardial ischaemia and spontaneous angina in patients with variant angina and in some patients with unstable angina.12 Pharmacological agents, such as calcium entry blocking drugs, which can decrease coronary resistance and relieve coronary artery spasm, are therefore useful in the management of variant and unstable angina. ${ }^{3-5}$ In patients with atherosclerotic coronary artery stenosis the capacity to increase coronary blood flow with increased myocardial oxygen requirements, as during effort induced angina, appears to be limited. ${ }^{6}$ The pharmacological treatment for effort angina has therefore usually relied

Requests for reprints to Dr Kanu Chatterjee, Room 1186, Moffitt Hospital, University of California, 505 Parnassus Avenue, San Francisco, California 94143, USA.

* Present address: Department of Medicine, Ostra Hospital, Göteborg, Sweden.

†Present address: Division of Cardiology, Montreal General Hospital, 1650 Cedar Avenue, Montreal, Quebec H36 14A, Canada.

Accepted for publication 17 April 1984 on decreasing myocardial oxygen demand. If, however, coronary blood flow can also be increased concomitantly the myocardial angina threshold is likely to improve. Nifedipine increases coronary blood flow in experimental animals and in humans by dilating epicardial coronary arteries and coronary arterioles. ${ }^{7-17}$ Thus the potential exists that nifedipine can improve angina threshold in patients with atherosclerotic obstructive coronary artery disease and effort angina. Angina threshold and coronary haemodynamics can be assessed during atrial pacing studies. ${ }^{6}$ The purpose of this study, therefore, was to evaluate the effects of oral nifedipine on pacing induced angina threshold in patients with atherosclerotic obstructive coronary artery disease and a history of stable effort angina.

\section{Patients and methods}

The study protocol was approved by the Human Research Committee at the University of California, San Francisco, and all patients gave written informed consent. The patient population consisted of 11 men (age range 48-65 (mean 58) years) with New York Heart Association class II or III chronic stable angina. Angina was classified as chronic if it had been present longer than three months and stable if the functional class had not recently deteriorated, there were no 
symptoms at rest, and the work threshold at which angina appeared was consistent by history. All patients had undergone coronary arteriography within the preceding three months. Nine patients had significant coronary artery disease $(\geqslant 70 \%$ luminal narrowing) of the three major epicardial coronary arteries and two patients two vessel disease. Three patients had old myocardial infarctions. No patient had previously been treated with a calcium entry blocking agent. Beta adrenergic blocking drugs were withheld for at least 24 hours and nitrates for at least 12 hours before the study.

All patients were admitted to the coronary care unit for placement of a triple lumen balloon flotation thermodilution catheter into the pulmonary artery and a coronary sinus thermodilution pacing catheter into the coronary sinus and for radial artery cannulation. The coronary sinus catheter was advanced into the midcoronary sinus to prevent reflux, ${ }^{18}$ and its position was checked fluoroscopically by injecting radiopaque dye before and after the study. After a brief rest, resting systemic and coronary haemodynamic data were collected and termed "baseline." Supraventricular pacing was then initiated at a rate $50 \%$ higher than the resting heart rate for five minutes and measurements at this time were defined as "subangina." The heart rate was then increased by 10 beats/min every minute until angina occurred or until a rate of 170 beats/min was achieved, and data collected at this pacing rate were defined as "angina." Electrocardiographic lead V5 was continuously monitored. Pacing was then discontinued. After a brief rest period, $20 \mathrm{mg}$ of nifedipine was given orally, and 30 minutes later the pacing protocol was repeated. The subangina pacing rate was the same as that used before drug administration. If patients did not develop angina at the predrug angina rate the pacing rate was further increased until angina occurred.

The following systemic haemodynamic measurements were recorded: systolic, diastolic, and mean arterial blood pressure (SBP, DBP, and MAP respectively); heart rate (HR); thermodilution cardiac output (CO); mean right atrial pressure (RAP); and pulmonary capillary wedge pressure (PCWP). The following variables were calculated: cardiac index $(\mathrm{CI})$ $\left(1 / \mathrm{min} / \mathrm{m}^{2}\right)=\mathrm{CO} / \mathrm{BSA}$, where BSA is body surface area; stroke volume index (SVI) $\left(\mathrm{ml} / \mathrm{m}^{2}\right)=\mathrm{CI} / \mathrm{HR}$; stroke work index $(\mathrm{SWI})\left(\mathrm{g} \mathrm{m} / \mathrm{m}^{2}\right)=\mathrm{SVI} \times(\mathrm{MAP}-$ PCWP) $\times 0.0136$; systemic vascular resistance (SVR) $\left(\right.$ dyn s cm$\left.~^{-5}\right)=(\mathrm{MAP}-\mathrm{RAP}) / \mathrm{CO} \times 80$; and double product $(\mathrm{DP})\left(\mathrm{mm} \mathrm{Hg} / \mathrm{min} \times 10^{-3}\right)=\mathrm{HR} \times \mathrm{SBP}$. The double product at the onset of angina and electrocardiographic manifestation of myocardial ischaemia was defined as the angina threshold. Coronary sinus blood flow (CSBF) was determined by the constant infusion thermodilution technique ${ }^{19}$ using the equation: $\operatorname{CSBF}(\mathrm{ml} / \mathrm{min})=\left(\left(\mathrm{T}_{\mathrm{B}}-\mathrm{T}_{\mathrm{I}} / \mathrm{T}_{\mathrm{B}}-\mathrm{T}_{\mathrm{M}}\right)\right.$ - 1) $\times 1.08 \times 46$ where $T_{B}$ is blood temperature, $T_{I}$ injectate temperature, $T_{M}$ temperature of the mixture, 1.08 a constant accounting for the specific heat and density of blood and injectate, and $46 \mathrm{ml} / \mathrm{min}$ the infusion rate of injectate ( $5 \%$ dextrose in water) by a Harvard constant infusion pump. Arterial and coronary sinus blood samples were drawn simultaneously for determination of oxygen saturation with a Corning 175 automated blood gas and $\mathrm{pH}$ analyser. Oxygen content $(\mathrm{ml} / 100 \mathrm{ml})$ was calculated as follows: \% oxygen saturation $\times$ haemoglobin $(\mathrm{g} / \mathrm{dl}) \times 1 \cdot 34$. The transmyocardial arteriovenous oxygen content difference ((ART-CS) $\mathrm{O}_{2}$, volume \%) was calculated as the difference between arterial and coronary sinus oxygen content. Myocardial oxygen consumption $\left(\mathrm{MVO}_{2}\right.$ $\mathrm{ml} / \mathrm{min}$ ) was calculated as follows: (ART-CS) $\mathrm{O}_{2} \times$ $\mathrm{CSBF}(\mathrm{ml} / \mathrm{min}) \times 10^{-3}$. Mean coronary vascular resistance (CVR) (dyn s cm$~_{-5}$ ) was calculated as (MAP$\mathrm{RAP}) / \mathrm{CSBF} \times 80$.

Statistical significance was evaluated by analysis of variance using Tukey's method for multiple comparisons. ${ }^{20}$

\section{Results}

During atrial pacing all patients developed angina both before and after nifedipine. After nifedipine angina occurred at a pacing rate higher than the predrug angina rate in only three patients. The angina heart rate in the remaining eight patients was unchanged after nifedipine. ST segment shifts in the electrocardiograms, indicative of myocardial ischaemia, occurred concurrently during angina. In all patients angina resolved promptly after pacing was stopped.

\section{SYSTEMIC HAEMODYNAMIC EFFECTS}

The systemic haemodynamic effects of nifedipine are summarised in the Table. After nifedipine, resting heart rate and systolic blood pressure decreased at baseline, subangina, and angina heart rates. In the group as a whole, the double product did not change at baseline but decreased significantly at subangina and angina rates. At angina rates in eight patients the double product was lower; in two patients it was unchanged and in only one was it slightly higher after nifedipine. Systemic vascular resistance was lower at subangina and angina rates. Left ventricular stroke work index decreased and pulmonary capillary wedge pressure increased at angina rates before nifedipine, and there was no significant change after nifedipine, indicating no change in left ventricular pump function. 
Table Systemic and coronary haemodynamic effects of nifedipine at rest (baseline) and at two different atrial pacing rates before and after nifedipine. Values are mean $(S D)(n=11)$

\begin{tabular}{|c|c|c|c|c|c|c|}
\hline \multirow[t]{2}{*}{ Variables measured } & \multicolumn{2}{|l|}{ Baseline } & \multicolumn{2}{|c|}{ Subangina rate } & \multicolumn{2}{|l|}{ Angina rate } \\
\hline & Before & After & Before & After & Before & After \\
\hline $\begin{array}{l}\text { Double product }\left(\mathrm{mm} \mathrm{Hg} / \mathrm{min} \times 10^{-3}\right) \\
\text { Stroke work index }\left(\mathrm{g} \mathrm{m} / \mathrm{m}^{\prime}\right) \\
\text { Systemic vascular resistance }\left(\text { dyn } \mathrm{s}^{-5}\right) \\
\text { Systolic blood pressure }(\mathrm{mm} \mathrm{Hg}) \\
\text { Pulmonary capillary wedge pressure }(\mathrm{mm} \mathrm{Hg}) \\
\text { Resting heart rate (beats/min) }\end{array}$ & $\begin{array}{l}11 \cdot 71(3 \cdot 14) \\
58 \cdot 8(17 \cdot 2) \\
1252(298) \\
159(19) \\
9 \cdot 7(5 \cdot 1) \\
73(15)\end{array}$ & $\begin{array}{c}\text { Systemic data } \\
11.43(2 \cdot 97) \\
53.7(15.9) \\
1062(348) \\
146(28)^{\star} \\
10 \cdot 0(5 \cdot 4) \\
79(16)^{\star} \\
\text { Coronary data }\end{array}$ & $\begin{array}{l}19 \cdot 45(4 \cdot 73) \\
47 \cdot 8(11 \cdot 3) \\
1308(408) \\
176(18) \\
10 \cdot 5(7 \cdot 3)\end{array}$ & $\begin{array}{l}16 \cdot 91(3.53)^{\star \star} \\
46 \cdot 5(10 \cdot 5) \\
1005(274)^{\star} \\
156(18) \\
10 \cdot 2(6 \cdot 8)\end{array}$ & $\begin{array}{l}23.30(3.36) \\
40 \cdot 0(13 \cdot 2) \\
1355(457) \\
177(17) \\
13 \cdot 6(10 \cdot 6)\end{array}$ & $\begin{array}{l}21 \cdot 28(3.00)^{\star \star} \\
37 \cdot 3(15 \cdot 8) \\
1028(291)^{\star \star \star} \\
157(19)^{\star \star \star} \\
13 \cdot 5(9 \cdot 4)\end{array}$ \\
\hline $\begin{array}{l}\text { Coronary sinus blood flow (ml/min) } \\
\left.\text { Coronary vascular resistance (dyn } \mathrm{s} \mathrm{cm}^{-5}\right) \\
\text { Coronary sinus oxygen content (volume \%) } \\
\text { Arterial coronary sinus oxygen }\end{array}$ & $\begin{array}{l}74 \cdot 9(41 \cdot 2) \\
131(74) \\
6 \cdot 32((1 \cdot 06)\end{array}$ & $\begin{array}{l}84 \cdot 4(42 \cdot 7) \\
98(45)^{\star \star \star} \\
8 \cdot 19(1 \cdot 55)^{\star \star \star \star}\end{array}$ & $\begin{array}{l}105 \cdot 3(52 \cdot 9) \\
101(60) \\
6 \cdot 67(1 \cdot 65)\end{array}$ & $\begin{array}{l}108 \cdot 5(43 \cdot 2) \\
80(40)^{\star \star} \\
7 \cdot 83(1 \cdot 35)^{\star \star \star}\end{array}$ & $\begin{array}{l}122 \cdot 5(50 \cdot 9) \\
82(38) \\
6 \cdot 86(1.69)\end{array}$ & $\begin{array}{l}126 \cdot 9(55 \cdot 5) \\
70(38) \\
7 \cdot 56(1 \cdot 42)^{\star \star}\end{array}$ \\
\hline $\begin{array}{l}\text { content difference (volume } \%) \\
\text { Myocardial oxygen consumption (ml/min) }\end{array}$ & $\begin{array}{l}12 \cdot 51(1 \cdot 80) \\
9 \cdot 57(6 \cdot 00)\end{array}$ & $\begin{array}{l}10.34(1 \cdot 70)^{\star \star \star \star} \\
8 \cdot 91(5 \cdot 10)\end{array}$ & $\begin{array}{l}12 \cdot 19(1.65) \\
12 \cdot 42(6 \cdot 90)\end{array}$ & $\begin{array}{l}10 \cdot 65(1 \cdot 67)^{\star \star \star \star} \\
11 \cdot 11(5 \cdot 25)\end{array}$ & $\begin{array}{l}12 \cdot 01(1 \cdot 63) \\
14 \cdot 62(6 \cdot 54)\end{array}$ & $\begin{array}{l}11 \cdot 22(1 \cdot 31)^{\star \star} \\
13 \cdot 10(5 \cdot 94)^{\star \star}\end{array}$ \\
\hline
\end{tabular}

\section{CORONARY HAEMODYNAMICS}

The effects of nifedipine on coronary haemodynamics are summarised in the Table and the Figure. Coronary sinus blood flow increased as the heart rate was increased to subangina and angina rates before nifedipine, and there was no significant change after nifedipine (Figure $a$ ). Before nifedipine, coronary sinus oxygen content did not change when heart rate was increased to subangina and angina rates. After nifedipine, this value increased appreciably at baseline and remained higher at subangina and angina rates (Figure $c$ ). Nevertheless, it decreased progressively as the heart rate was increased to subangina and angina rates $(p<0.01)$. Myocardial oxygen extraction also decreased appreciably after nifedipine at baseline and subangina rates; at angina rates the decrease was less pronounced (Figure $d$ ). Myocardial oxygen con,sumption did not change significantly at baseline and subangina rates, but it was lower at angina rates after nifedipine (Figure $f$ ).

\section{Discussion}

That nifedipine is a potent coronary vasodilator and dilates epicardial coronary arteries and decreases coronary arterial tone has been suggested both in experimental animals and in humans. ${ }^{7-17}$ The present study shows that even in patients with atherosclerotic obstructive coronary artery disease nifedipine can cause vasodilatation of the coronary vascular bed. This was evident from the decreased mean coronary vascular resistance at rest and at subangina heart rates after nifedipine. After nifedipine, arterial pressure fell at all heart rates, and the double product decreased at subangina and angina rates; but the expected fall in coronary blood flow due to decreased myocardial oxygen demand did not occur. Most importantly, coronary sinus oxygen content increased and myocardial oxygen extraction decreased consistently, suggesting that the global myocardial perfusion was in excess of that required to meet myocardial oxygen demand. Increased coronary sinus oxygen saturation and decreased myocardial oxygen extraction after nifedipine have been observed in other investigations. ${ }^{21}$ These findings suggest that nifedipine has the potential to increase coronary blood flow by primary coronary vasodilatation even in patients with obstructive coronary artery disease. From this study, however, the site of coronary vasodilatation-the epicardial coronary arteries or coronary arteriolar bed-cannot be determined.

Nevertheless, the present study also shows that nifedipine can induce angina at a lower angina threshold in many patients with atherosclerotic obstructive coronary artery disease. After nifedipine, double product -an index of myocardial oxygen demand-was not only lower at subangina but also at angina pacing rates in most of our patients. Although previous studies have suggested that the double product may not change, ${ }^{21}$ decreased angina threshold-evident from decreased double product and decreased myocardial oxygen consumption at angina rates after nifedipine- - has not been found. In the study of Emanuelsson and Holmberg, however, in five of their 14 patients myocardial lactate production, indicating myocardial ischaemia, occurred at a lower double product after nifedipine. ${ }^{21}$ In three of their patients myocardial lactate production occurred at rest after nifedipine despite $\mathrm{a}$ significant fall in systolic blood pressure. Kaltenbach et al showed that the coronary vasodilatation produced by nifedipine is temporally dissociated from its antianginal effect. ${ }^{22}$ 

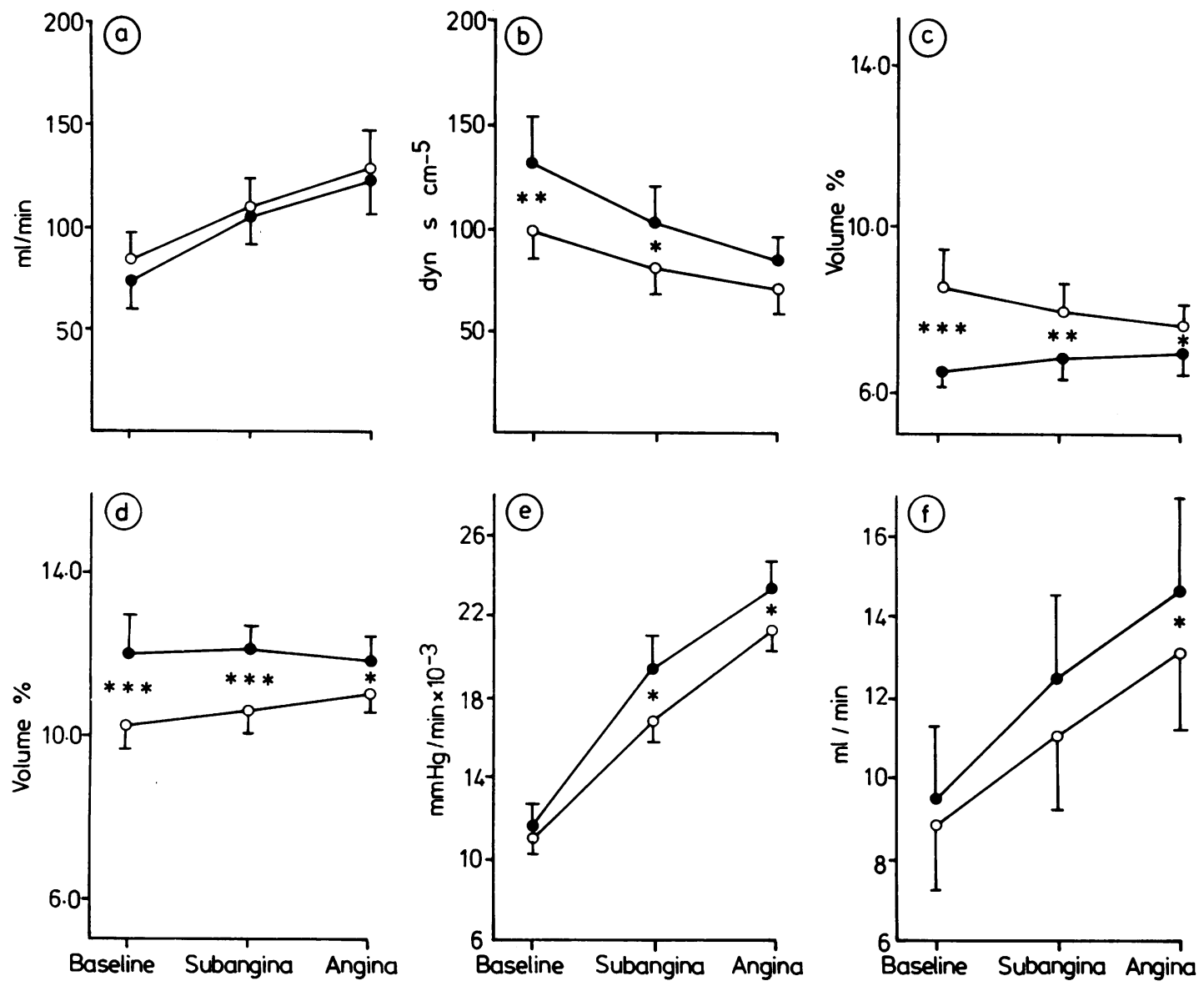

Fig. Effects of nifedipine on (a) coronary sinus flow, (b) coronary vascular resistance, (c) coronary sinus oxygen content, (d) myocardial oxygen extraction, $(e)$ double product, and $(f)$ myocardial oxygen consumption at rest (baseline), and at subangina, and angina heart rates before $(O)$ and after $(O)$ nifedipine. Values are means $(S E M)(n=11) .{ }^{\star} p<0.05,{ }^{\star \star} p<0.01$, $\star \star \star p<0.001$.

Simonsen and Nitter-Hauge also reported that whereas nifedipine produces coronary vasodilatation at rest this effect becomes insignificant as the angina threshold is reached. ${ }^{23}$ In contrast to these studies, Engle and Lichtlen suggested that during pacing induced myocardial stress nifedipine might enhance coronary blood flow to the poststenotic area. ${ }^{17}$ These investigators compared changes in regional myocardial blood flow, determined by xenon washout techniques, in normal and poststenotic areas after nifedipine. It is not clear, however, whether the heart rate was increased to angina rates after nifedipine in the study of Engle and Lichtlen. ${ }^{17}$ Furthermore, the increment in blood flow to the poststenotic area at prenifedipine angina heart rate was not statistically significant, whereas the flow to the normal areas decreased. Thus the difference in the changes in flow to the normal and poststenotic areas became statistically significant. It is also noteworthy that in the study of Engle and Lichtlen ${ }^{17}$ the double product at the highest pacing rate after nifedipine was $22 \%$ lower than that before nifedipine, indicating no improvement but a decrement in angina threshold. Lack of improvement in angina threshold during pacing induced angina in patients with obstructive coronary artery disease is not only observed with nifedipine but also with other calcium entry blocking agents. Verapamil, which also possesses coronary vasodilating effects and has the potential to increase coronary blood flow, does not improve angina threshold or coronary reserve in patients with effort angina. ${ }^{24}$ Prostacyclin, a vasodilating prostaglandin, also decreases coronary vascular resistance and increases coronary blood flow with concomitant reduction in 
myocardial oxygen extraction at rest; but it also does not increase angina threshold during atrial pacing. ${ }^{25}$ It is apparent, therefore, that the pharmacological agents that can potentially increase coronary blood flow by primary coronary vasodilatation are unlikely to improve angina threshold in patients with fixed obstructive coronary artery disease. Indeed, potential exists for the reduction of angina threshold with potent coronary vasodilators. Clinical studies also suggest that in some patients angina may be precipitated after nifedipine. ${ }^{26}$

The mechanism for this paradoxical response is not entirely clear. A reflex increase in myocardial contractile function or tachycardia and a possible increase in myocardial oxygen demand cannot be incriminated as the important cause since coronary sinus venous oxygen content was higher and global myocardial oxygen extraction lower at the time of angina.

One possible explanation is that nifedipine induced coronary vasodilatation increased blood flow to the non-ischaemic zone in excess of what was needed to meet the metabolic demand without increasing the flow to the potentially ischaemic zones. In the ischaemic zones the exhaustion of the autoregulatory reserve due to metabolically mediated reduction of coronary vascular resistance prevents further reduction of coronary vascular resistance. Diversion of blood flow from the ischaemic zones to the relatively non-ischaemic myocardial zones, as a potential cause for induction of myocardial ischaemia at rest or at a lower double product, cannot be entirely excluded. That the potent coronary vasodilators can cause such a diversion of flow from the ischaemic myocardial zones has been suggested in previous studies. ${ }^{27} 28$

In conclusion, the results of the present study suggest that nifedipine is a potent coronary vasodilator, and it decreases coronary vascular resistance even in patients with fixed obstructive coronary artery disease. In patients with significant obstructive coronary artery disease, however, it does not improve angina threshold. In some patients angina can occur at a lower myocardial oxygen demand.

KS was a recipient of the Fogarty International Fellowship Award and J-LR of the McGill Traveling Fellowship.

\section{References}

1 Maseri A, L'Abbate A, Chierchia S, et al. Significance of spasm in the pathogenesis of ischemic heart disease. Am f Cardiol 1979; 44: 788-92.

2 Parodi O, Maseri A, Simonetti I. Management of unstable angina at rest by verapamil: a double-blind crossover study in coronary care unit. Br Heart $\mathcal{F} 1979$; 41: 167-74.
3 Goldberg S, Reichek N, Wilson J, Hirshfeld JW Jr, Muller J, Kastor JA. Nifedipine in the treatment of Prinzmetal's (variant) angina. Am f Cardiol 1979; 44: 804-10.

4 Muller JE, Gunther SJ. Nifedipine therapy for Prinzmetal's angina. Circulation 1978; 57: 137-9.

5 Johnson SM, Mauritson DR, Willerson JT, Hillis LD. Comparison of verapamil and nifedipine in the treatment of variant angina pectoris: preliminary observations in ten patients. Am F Cardiol 1981; 47: 1295-300.

6 Rouleau J-L, Chatterjee K, Ports TA, Parmley W. Coronary reserve angina threshold in patients with fixed obstructive coronary artery disease: alterations in coronary vascular tone do not play a significant role [Abstract]. F Am Coll Cardiol 1983; 1: 672.

7 Imai S. Effects of nifedipine on heart and coronary circulation. In: Hashimoto K, Kimura E, Kobayashi T, eds. New therapy of ischemic heart disease. Tokyo: University of Tokyo Press, 1975: 23.

8 Fleckenstein A, Grun G, Byon KY, Doring HJ, Tritthart $\mathrm{H}$. The basic $\mathrm{Ca}$ antagonist actions of nifedipine on cardiac energy metabolism and vascular smooth muscle tone. In: Hashimoto K, Kimura E, Kobayashi T, eds. New therapy of ischemic heart disease. Tokyo: University of Tokyo Press, 1975: 31.

9 Nayler WG, Ferrari R, Williams A. Protective effect of pretreatment with verapamil, nifedipine and propranolol on mitochondrial function in the ischemic and reperfused myocardium. Am $\mathcal{F}$ Cardiol 1980; 46: 242-8.

10 Henry PD, Clark RE. Protection of ischemic myocardium by treatment with nifedipine. In: Winbury $M M$, Abiko Y, eds. Ischemic myocardium and antianginal drugs. New York: Raven Press, 1979: 143.

11 Henry PD, Schuchleib R, Borda LJ, Roberts R, Williamson JR, Sobel BE. Effects of nifedipine on myocardial perfusion and ischemic injury in dogs. Circ Res 1978; 43: 372-80.

12 Gunther S, Green L, Muller JE, Mudge GH Jr, Grossman W. Inappropriate coronary vasoconstriction in patients with coronary artery disease: a role for nifedipine? Am $\mathcal{F}$ Cardiol 1979; 44: 793-7.

13 Stone PH, Antman EM, Muller JE, Braunwald E. Calcium channel blocking agents in the treatment of cardiovascular disorders. Part 2: Hemodynamic effects and clinical applications. Ann Intern Med 1980; 93: 886-904.

14 Henry PD. Comparative pharmacology of calcium antagonists: nifedipine, verapamil and diltiazem. Am $\mathcal{Y}$ Cardiol 1980; 46: 1047-58.

15 Sobel BE. Mechanisms of action and clinical implications of calcium antagonists. Practical Cardiology 1981; 7: 31.

16 Bertrand ME, Lablamche JM, Tilmant PY. Treatment of spasm of the coronary artery with nifedipine. Eur Heart $\mathcal{F}$ 1980; suppl B: 65 .

17 Engle H-J, Lichtlen PR. Beneficial enhancement of coronary blood flow by nifedipine. Comparison with nitroglycerin and beta blocking agents. Am $\mathcal{F}$ Med 1981; 71: 658-66.

18 Mathey DG, Chatteriee K, Tyberg JV, Lekven J, Brundage BH, Parmley WW. Coronary sinus reflux: a source of error in the measurement of thermodilution coronary sinus flow. Circulation 1978; 57: 778-86.

19 Ganz W, Tamura K, Marcus HS, Donoso RR, Yoshida S, Swan HJC. Measurement of coronary sinus blood flow 
by continuous thermodilution in man. Circulation 1971; 44: 181-95.

20 Dixon WJ. BMDP statistical softward 1981. Berkeley: University of California Press, 1981.

21 Emanuelsson H, Holmberg S. Mechanisms of angina relief after nifedipine: a hemodynamic and myocardial metabolic study. Circulation 1983; 68: 124-30.

22 Kaltenbach M, Schultz W, Kober G. Effects of nifedipine after intravenous and intracoronary administration. Am f Cardiol 1979; 44: 832-8.

23 Simonsen S, Nitter-Hauge S. Effect of nifedipine (adalat) on coronary haemodynamics in patients with coronary arteriosclerotic disease. Acta Med Scand 1978; 204: 179 84.

24 Rouleau J-L, Chatterjee K, Ports TA, Doyle MB, Hiramatsu B, Parmley WW. Mechanism of relief of pacing-induced angina with oral verapamil: reduced oxygen demand. Circulation 1983; 67: 94-100.

25 Bergman G, Daly K, Atkinson L, et al. Prostacyclin: haemodynamic and metabolic effects in patients with coronary artery disease. Lancet 1981; i: 569-72.

26 Jariwalla AG, Anderson EG. Production of ischaemic cardiac pain by nifedipine. $\mathrm{Br}$ Med $\mathcal{F}$ 1978; i: 1181-3.

27 Mann T, Cohn PF, Holman BL, Green LH, Markis JE, Phillips DA. Effect of nitroprusside on regional myocardial blood flow in coronary artery disease. Results in 25 patients and comparison with nitroglycerin. Circulation 1978; 57: 732-8.

28 Arrotti J, Gunnar RM, Ward J, Loeb HS. Comparative effect of intravenous dipyridamole and sublingual nitroglycerin on coronary hemodynamics and myocardial metabolism at rest and during atrial pacing in patients with coronary artery disease. Clin Cardiol 1980; 3: 36570. 